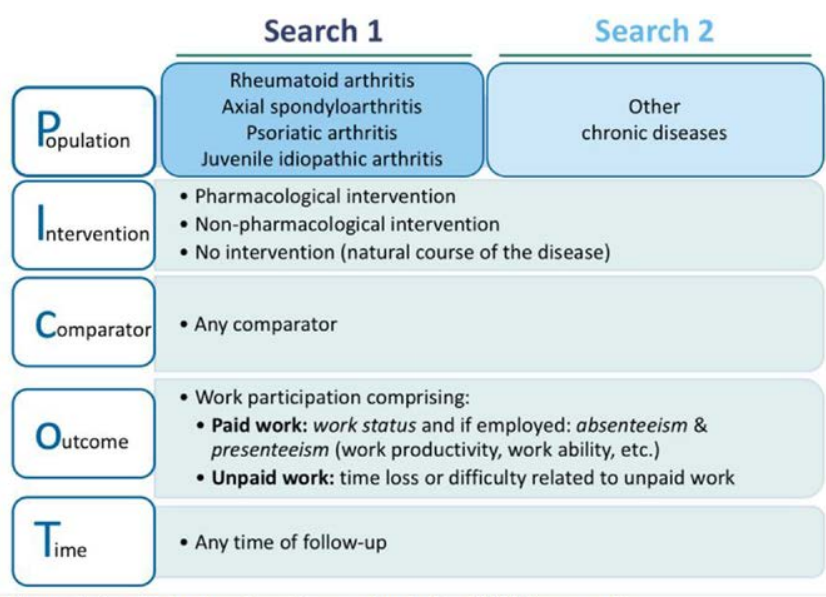

Figure 1. Search strategy 1 and 2 according to the PICOT framework.

Disclosure of Interests: Alessia Alunno: None declared, Mary Lucy Marques: None declared, Annelies Boonen Grant/research support from: AbbVie, Consultant of: Galapagos, Lilly (all paid to the department), L. Falzon: None declared, Sofia Ramiro Grant/research support from: MSD, Consultant of: Abbvie, Lilly, Novartis, Sanofi Genzyme, Speakers bureau: Lilly, MSD, Novartis, Polina Putrik: None declared

DOI: 10.1136/annrheumdis-2020-eular.4730

\section{AB1178 1 AN AUDIT OF ORIGINATOR ADALIMUMAB TO BIOSIMILAR SWITCH IN TWO HOSPITALS}

R. Mazumder ${ }^{1}$, M. Loke ${ }^{1}$, C. Mukhtyar ${ }^{1}$, K. Gaffney ${ }^{1}$, E. Balogh ${ }^{2}$, E. Sekaran ${ }^{2}$, M. Sultana ${ }^{3}$, M. Odonkor ${ }^{2}$, K. Miles $^{1} .{ }^{1}$ Norfolk \& Norwich University Hospital, Norwich, United Kingdom; ${ }^{2}$ Broomfield Hospital, Broomfield, United Kingdom; ${ }^{3}$ University of Essex, Colchester, United Kingdom

Background: Biological drugs have revolutionized the treatment of immune-mediated inflammatory diseases (IMIDs). Current guidelines reserve these drugs for patients with severe refractory disease.

Biologic drugs are expensive, but as they reach patent expiry, the introduction of lower-cost biosimilars reduces their impact on health care budgets. It is estimated that NHS England could save $£ 300$ million by 2021 following the recent launch of adalimumab biosimilars [1]. As part of this process, there has been a mandatory switch of originator adalimumab to biosimilar adalimumab throughout the U.K.

Objectives: To evaluate the impact of the switch to biosimilar adalimumab in individuals with inflammatory arthritis at two NHS trusts in the East of England and calculate the proportion and reasons for switch back to originator adalimumab or a second biosimilar at 12 weeks.

Methods: Both hospitals ran dedicated 'switch' clinics. All patient records were reviewed retrospectively.

Results: 855 patients with different IMID switched from originator to biosimilar over 13 months. At 12 weeks, 730 patients (85\%) maintained the switch, 71 patients $(8.7 \%)$ switched back to the originator, and 54 patients $(6.3 \%)$ switched to other biosimilars of the same drug.

Table 1. Primary outcome analysis of switching from originator to adalimumab biosimilar

\begin{tabular}{|c|c|c|c|c|c|}
\hline Diagnosis & $\begin{array}{l}\text { Total } \\
\text { patient } \\
\text { switched } \\
\text { from } \\
\text { originator }\end{array}$ & $\begin{array}{c}\text { Average duration } \\
\text { (year) of use of } \\
\text { originator before } \\
\text { bio switch (for } \\
\text { patients continue } \\
\text { using bio switch) }\end{array}$ & $\begin{array}{l}\text { Total } \\
\text { patients } \\
\text { continuing } \\
\text { (At } 12 \\
\text { weeks) }\end{array}$ & $\begin{array}{l}\text { Average duration } \\
\text { (year) of use of } \\
\text { originator before } \\
\text { bio switch (for } \\
\text { patients switched } \\
\text { back to originator) }\end{array}$ & $\begin{array}{c}\text { Total } \\
\text { patients } \\
\text { switched } \\
\text { back to } \\
\text { origina- } \\
\text { tor or } \\
\text { other } \\
\text { biosimilar }\end{array}$ \\
\hline $\begin{array}{l}\text { Rheumatoid } \\
\text { Arthritis }\end{array}$ & 356 & 7.9 & 314 (88\%) & 4.9 & $\begin{array}{c}42 \\
(12 \%)\end{array}$ \\
\hline $\begin{array}{l}\text { Axial } \\
\text { Spondyloarthritis }\end{array}$ & 260 & 6.4 & 213 (82\%) & 4.5 & $\begin{array}{c}47 \\
(18 \%)\end{array}$ \\
\hline Psoriatic Arthritis & 218 & 5.9 & $187(86 \%)$ & 2.9 & $\begin{array}{c}31 \\
(14 \%)\end{array}$ \\
\hline Juvenile Arthritis & 16 & 3.7 & $14(88 \%)$ & 4.5 & $2(12 \%)$ \\
\hline Others & 5 & 2.2 & $2(40 \%)$ & 0.8 & $3(60 \%)$ \\
\hline Total & 855 & 7.0 & $730(85 \%)$ & 4.2 & 125 \\
\hline
\end{tabular}

Table 2. Reasons for back to originator or another biosimilar

\begin{tabular}{lclc}
\hline \multicolumn{2}{c}{ Reasons for back to originator or another biosimilar } \\
\hline \multicolumn{1}{c}{ Number back for Intolerance } & \multicolumn{1}{c}{ Number back for Inefficacy } \\
\hline $\begin{array}{l}\text { Painful injection } \\
\text { Pain/Others }\end{array}$ & 69 & BASDAI/Spinal Pain & 13 \\
$\begin{array}{l}\text { Rash/Allergic } \\
\text { reaction }\end{array}$ & 19 & TJC, SJC, VAS & 4 \\
Headache & 5 & DAS & 3 \\
Nausea & 5 & PsARC & 2 \\
Total & 4 & No Detail & 1 \\
$\%$ & 102 & Total & 23 \\
& $82 \%$ & & $18 \%$ \\
\hline
\end{tabular}

Conclusion: Switching to a biosimilar was successful in the vast majority of patients and is associated with significant saving. The list prices for originator Adalimumab is $£ 9,155 /$ person/year and $£ 8,238$ /person/year for biosimilar Adalimumab respectively [2]. By switching we will save approximately $£ 719,402$ per annum (9.2\% cost reduction).

\section{References:}

[1] NHS England. NHS set to save record $£ 300$ million on the NHS's highest drug spend 2018 [cited 2018 November 30]. https://www. england.nhs.uk/2018/11/nhs-set-to-save-record-300-million-on-thenhss-highest-drug-spend/

[2] https://bnf.nice.org.uk/medicinal-forms/adalimumab.html

Disclosure of Interests: Rifat Mazumder: None declared, Marianne Loke: None declared, Chetan Mukhtyar: None declared, Karl Gaffney Grant/ research support from: AbbVie, Celgene, MSD, Novartis, Pfizer, and UCB Pharma, Consultant of: AbbVie, Celgene, MSD, Novartis, Pfizer, and UCB Pharma, Speakers bureau: AbbVie, Celgene, MSD, Novartis, Pfizer, and UCB Pharma, Emese Balogh: None declared, Emerald Sekaran: None declared, Mushfika Sultana: None declared, Mabel Odonkor: None declared, Karen Miles: None declared

DOI: 10.1136/annrheumdis-2020-eular.4709

\section{AB1179 1 EMERGENCY DEPARTMENT LENGTH OF STAY FOR PATIENTS WITH ACUTE GOUT}

N. Mbuyi ${ }^{1}$, S. Reinert ${ }^{2}$, R. Hilliard ${ }^{3}$, A. Reginato ${ }^{3}$, D. Dalal ${ }^{3} .{ }^{1}$ George Washington University School of Medicine, Department of Medicine, Washington, DC, United States of America; ${ }^{2}$ Lifespan Health System, Providence, RI, United States of America; ${ }^{3}$ Warren Alpert Medical School of Brown University, Department of Medicine, Providence, RI, United States of America

Background: Emergency department (ED) visits for acute gout increased by approximately 20\% between 2006 and 2014 in the United States. (1) Reducing ED length of stay (LOS) can help improve health outcomes, and reduce ED crowding and cost of care for patients with gout.

Objectives: The aim of our study was to assess ED LOS and to identify factors associated with prolonged ED LOS in patients with acute gout.

Methods: In this retrospective analysis, we included the first ED visit of adult patients $(>18$

years) with acute gout who presented to the 3 EDs affiliated with Lifespan Health Systems, the largest healthcare provider in Rhode Island. Our study period was $3 / 30 / 2015$ to $9 / 30 / 2017$.

We calculated ED LOS as the time spent by patients in the ED until they were discharged. Patients presenting to the ED and subsequently admitted to the hospital were excluded given the differential effect of systems factors in these patients. We assessed the following factors' association with being in the upper quartile of ED LOS: (a) Patient factors - demographics, comorbidities and clinical presentation of gout (number of joints involved, severity as gauged by an ED triage nurse on a scale of 1 to 5 ; 1 being the worst) and (b) systems factors - time of day, day of the week, and time of year at presentation to the ED, teaching versus non-teaching hospital setting, and performing an arthrocentesis. We performed univariate and multivariable analyses to identify factors associated with prolonged ED LOS in patients with acute gout.

Results: A total of 355 patients (mean age $56.6 \pm 16.03$ years, $81.3 \%$ males) were included. The median ED LOS was 2.65 hours (1.75, 4.3 hours). A quarter of the patients spent more than 4.3 hours in the ED; the national average across all medical illnesses being 3.7 hours (2). In the univariate analysis, older age (> 65 years), comorbidities (hypertension, congestive heart failure), worse ED severity score, procedural delays, and teaching hospital setting were associated with being in the upper quartile of ED LOS. In a multivariable analysis, age $>65$ years, procedural delays, and worse ED acuity score continued to be associated with longer ED LOS.

Conclusion: In our study settings, patients with acute gout spent a longer time in the ED than the national median of 120-150 minutes. (2) We noted that older age and higher acuity score in addition to procedural delays led to longer length of stay in the ED. The results of our study should guide future interventions to reduce ED LOS for patients with acute gout. 
References:

[1] Mithal, A., \& Singh, G. (2018). OP0185 Emergency department visits for gout: a dramatic increase in the past decade

[2] Centers for Disease Control and Prevention. (2014). QuickStats: median emergency department (ED) wait and treatment times, by triage level-National Hospital Ambulatory Medical Care Survey, United States, 20102011. Morb Mortal Wkly Rep, 63,439. (https://www.cdc.gov/mmwr/preview/ $\mathrm{mmwrhtml} / \mathrm{mm} 6319 \mathrm{a} 8 . \mathrm{htm})$

Disclosure of Interests: None declared

DOI: 10.1136/annrheumdis-2020-eular.2682

\section{$\mathrm{AB} 1180$ \\ THE EVOLUTION OF AN FLS IN SEARCH OF EXCELLENCE: THE EXPERIENCE OF GRAN CANARIA.}

A. Naranjo ${ }^{1}$, A. Molina ${ }^{1}$, C. Sepúlveda ${ }^{1}$, C. Torres ${ }^{1}$, F. Santana ${ }^{1}$, F. Rubiño ${ }^{1}$, R. López ${ }^{1}$, S. Ojeda ${ }^{1} .{ }^{1}$ Hospital Universitario de Gran Canario Dr Negrin, Las Palmas, Spain

Background: The implementation of an FLS in the Spanish public health system is not an easy task since there are no official plans for the incorporation of personnel dedicated to the unit

Objectives: To expose the consolidation and improvement of an FLS after its implementation as well as the problems that have arisen over time.

Methods: The health program for secondary fracture prevention was implemented in 2012. Initially worked with the same staff assigned to the Rheumatology service, since 2016 we have a part-time support nurse. Patients are identified from the emergency registry and, more recently, from patients admitted for hip fracture and treated in a monographic osteoporosis clinic. The baseline visit consists of consultation with the nurse, DXA and bone metabolism analytics. Falling patients are referred to a fall prevention school. Most patients are referred to their primary care physician to start a treatment.

Results: Of the 2,416 patients attended the baseline visit, $30 \%$ were forearm fractures, $27 \%$ hip, $20 \%$ humerus, $10 \%$ spine and $11 \%$ other fractures. In comparison to 2012, in 2019 the monthly average of patients has doubled, increased the number of hip and spine fractures, and increased the percentage of captured patients (Table). In spite of consolidating the unit, getting a support nurse for the admitted patients and establishing a solid alliance with primary care, it is pending the involvement of Primary Care Nurses and start first prescription at the hospital.

Table. Comparison of the first year with the last year of implementation of our FLS.

\begin{tabular}{lcc}
\hline & 2012 & 2019 \\
\hline Mean monthly number of fractures, N & 22 & 42 \\
Type of fracture: forearm/hip/spine, \% & $37 / 20 / 6$ & $28 / 40 / 11$ \\
Captured patients of elegible, \% & 57 & 77 \\
Delay in weeks until first visit to FLS, median & 14 & 12 \\
Patient origin: emergency list/inpatient/outpatient, \% & $100 / 0 / 0$ & $59 / 31 / 9$ \\
DXA performed, \% & 100 & 61 \\
Referral to fall prevention school, \% & 0 & 26 \\
Criteria to start a treatment, \% & 67 & $90^{\star}$ \\
Referral to the osteoporosis clinic, \% & 37 & 7
\end{tabular}

*We apply the 2019 recommendations of the Spanish Society of Rheumatology

Conclusion: We present the achievements made by our FLS along 8 years and the difficulties within the Spanish public health system.

Disclosure of Interests: Antonio Naranjo Grant/research support from: amgen, Consultant of: UCB, Speakers bureau: AMGEN, Amparo Molina Speakers bureau: AMGEN, STADA, Cristina Sepúlveda: None declared, Candelaria Torres: None declared, Fabiola Santana: None declared, Francisco Rubiño: None declared, Rubén López: None declared, Soledad Ojeda Speakers bureau: AMGEN, LILLY, GEBRO

DOI: 10.1136/annrheumdis-2020-eular.771

\section{AB1181 SHOULD A COMBINED RHEUMATOLOGY- PULMONOLOGY INTERSTITIAL LUNG DISEASE SERVICE BE CONFINED TO TERTIARY CENTRES - A SERVICE EVALUATION}

K. Salama ${ }^{1}$, N. Ramsundar ${ }^{1}$, V. Joshi ${ }^{1}$, M. K. Nisar ${ }^{1} .{ }^{1}$ Luton and Dunstable University Hospital, Luton, United Kingdom

Background: Interstitial lung disease is a well described extra-articular manifestation in a range of rheumatic diseases. It carries significant morbidity and mortality. Management of rheumatic diseases associated ILD (r-ILD) requires expertise as the needs of such patients are complex and treatment options limited. Historically, such complex ILD has been managed in tertiary referral centres.

Objectives: We set up a combined service incorporating both rheumatology and respiratory domains in a district general hospital (DGH) to help patients avoid long journeys and improve their experience whilst focusing on an integrated care pathway. We evaluated the outcomes of the first set of patients managed in this proof-of-concept service model.

Methods: Referrals were accepted from any hospital specialist involved in the management r-ILD. They were triaged by lead ILD pulmonologist to monthly ILD MDT comprising a rheumatologist, respiratory physician, a radiologist and ILD specialist nurse. Appropriate patients were booked into combined clinic, run by the respective rheumatology and chest specialists with ILD interest, attracting a multi-speciality tariff. All the data was recorded electronically with full access to demographics, disease parameters, investigations and drug management.

Results: 89 patients were included in this proof-of-concept. Mean age was 66.1 yrs (19-90 yrs) and 44\% ( $n=39)$ were male. 35 (40\%) had RA, $34(39 \%)$ had CTD, eight (10\%) had sarcoidosis, five had IPAF and seven others. Most predominant HRCT pattern was NSIP $(n=53,60 \%)$ followed by UIP $(n=23,21 \%)$, sarcoid $(n=10,12 \%)$ and miscellaneous (LIP and mixed). Mean FVC was $2.64 \mathrm{~L}$ min (1.93-4.13) with DLCOc of $52.7 \%$ (28.9-90.1\%) predicted. Only two patients had all antibodies negative whilst 87 had at least one antibody positive with ANA being the most common $(n=28)$.

Most $(83 \%)$ patients were treated with immunomodulators including nine with rituximab. $39(44.3 \%)$ patients had significant improvement in clinical, imaging and pulmonary parameters with DLCOc improving to $56.57 \%$ and FVC to $2.70 \mathrm{~L}$ min. There were similar improvements in six minute walk test. 17 patients died and 20 patients required long term oxygen therapy.

Conclusion: This proof-of-concept real world study confirms the utility of a combined specialist service in a district general hospital. Nearly half of this complex and resource intensive patient cohort had good clinical outcomes and derived benefit from the expertise in one room. Feedback from both patients and referrers was unanimously positive. No patient required tertiary centre referral and all could be managed adequately in the clinical setting.

Our report confirms that r-ILD can be managed in a DGH setting with a streamlined service offering clear benefits to patients. We would argue that r-ILD service, congruent to satellite pulmonary hypertension clinics in secondary care with hub-and-spoke model liaison with tertiary centre, can be established on similar principles and could help over-stretched tertiary care with repatriation of services whilst helping develop local expertise in the management of chronic ILD.

Disclosure of Interests: Karim Salama: None declared, Natasha Ramsundar: None declared, Vijay Joshi: None declared, Muhammad Khurram Nisar Grant/ research support from: Muhammad Nisar undertakes clinical trials and received support (including attendance at conferences, speaker fees and honoraria) from Roche, Chugai, MSD, Abbvie, Pfizer, BMS, Celgene, Novartis and UCB

Consultant of: Muhammad Nisar undertakes clinical trials and received support (including attendance at conferences, speaker fees and honoraria) from Roche Chugai, MSD, Abbvie, Pfizer, BMS, Celgene, Novartis and UCB

, Speakers bureau: Muhammad Nisar undertakes clinical trials and received support (including attendance at conferences, speaker fees and honoraria) from Roche, Chugai, MSD, Abbvie, Pfizer, BMS, Celgene, Novartis and UCB DOI: 10.1136/annrheumdis-2020-eular.2023

\section{$\mathrm{AB} 1182$ \\ OPTICAL COHERENCE TOMOGRAPHY FOR HYDROXYCHLOROQUINE EYE MONITORING - SHOULD WE WORRY?}

A. Moharram ${ }^{1}$, F. Raj ${ }^{1}$, J. Maya ${ }^{1}$, R. Sandhu ${ }^{1}$, M. K. Nisar ${ }^{1} .{ }^{1}$ Luton and Dunstable University Hospital, Luton, United Kingdom

Background: Recent data have highlighted that hydroxychloroquine (HCQ) retinopathy is much more common than previously reported. The overall prevalence appears to be around $7.5 \%$ and depending on dose and duration of therapy can increase to $20-50 \%$ after 20 years of therapy. Royal College of Ophthalmology UK recommend that all patients planning to take hydroxychloroquine long term have a baseline examination in a hospital eye department with a colour retinal photograph and spectral domain optical coherence tomorgraphy (SD-OCT) scans of the macula. After five years, annual screening is required with 10-2 Humphrey visual field testing, followed by pupillary dilation and imaging with both SD-OCT and widefield fundus autofluorescence imaging (FAF)

Objectives: Our aim was to review the early findings of the screening program for all rheumatology patients prescribed HCQ at our university hospital.

Methods: A business case was approved to set up eye monitoring in accordance with above guidelines. All patients with rheumatic diseases prescribed $\mathrm{HCQ}$ were identified through departmental database. They were invited for ophthalmological 